\title{
Remembering Childhood Play
}

\author{
Alexandra Fidyk
}

\begin{abstract}
In looking back to childhood, and what constituted daily life, a case is made for unique ways of knowing that unfold through play, place, and tradition. A closer look at the relationship between childhood memory and the particularities of place, suggests that adult creativity, a sense of psychological stability, and an attitude of wonder, even experimentation, are vital outgrowths. The loss of play from the realm of the child is considered a contributing factor to the current trauma epidemic within our society. How might returning to imagination, the body, free play, and the ecology of relationship renew the ways we live and make meaning, in addition to the ways we heal and become more whole?
\end{abstract}

\section{Remembering Childhood Play}

Imagination and the body together are how children grow and heal.

Dennis McCarthy (2007), "If you turned into a monster" (p. 17)

Trauma studies confirm a powerful truth for education: "fear destroys curiosity and playfulness. There can be no growth without curiosity and no adaptability without being able to explore" (van der Kolk, 2015, p. 350). When teachers are stretched beyond capacity by large classroom enrollment, and increased diversity and complexity of individual student needs, they are more readily overwhelmed. Add constant external monitoring via standardized testing and outcome accountability which influence pedagogy and assessment, and we must ask: how are children to develop ways of knowing inclusive of and inherent to play, imagination, negotiation, and wonder? For these ways of knowing and becoming are fundamental to childhood and require a spaciousness of time and attitude. Central to both imagination and body is play, a rare activity both outside and inside of school. Indeed, we have appropriated play from children and youth and left them with an inadequate substituteorganized, scheduled, play-dates or none at all (Teitel, 1999). Contributing factors to this situation include corporate models affecting the organization and aims of education, individualized family units separated from place and extended family members, as well as societal values refigured by neoliberalism. Today, the population among us most readily able to play is adults, and often those who are retired, if they have the means. A generation ago play was the exclusive domain of children. Now adults play and kids don't.

When I grew up in rural Saskatchewan, it was common for kids to have chores indoors (dishes, dust, sweep, cook) and out (collect eggs, water and feed the animals, cut grass, weed, milk the cows). When done, we did homework or played (which included creative activities). Our chores encouraged curiosity, experimentation, and risk-taking. They taught us knowledge, skills, and values for we not only 
tended the cows, but also we witnessed them, attuned to them. If something unusual occurred, we noticed it-that included breeding, birthing, and dying. Many summers were spent either helping friends finish chores or them me, and then off we went on bikes, riding around the countryside for five or six hours, with no water bottles, no cell phones, no plan, and no communication with parents until we arrived home. Often, we would ride 10-plus miles on a Saturday afternoon-a regular occurrence as there were no restrictions on these adventures. As Matt Hern (2007) describes, these were "unfettered days ... running around, riding our bikes beyond our parents' call, messing around in fields, always far from adult supervision" (p. 43). Our parents were busy so when our chores were done, we had complete freedom to roam on bike, foot, or horse. There, too, were enough kids of similar age that we could meet midway at a farm and play scrub (softball when there are not enough players for two teams) till the sun began to set, then everyone fled for home on bikes. The local rule: home before dark. We had a sense of safety and stability with place-a psychological freedom and comfort-because we belonged to it and in some way, place - the Sandy Road, the gravel roads between the Hetchlers, Tyackes, and Garnettsbelonged to us. We grew up by this rhythm; we explored, risked, questioned, played, and taught each other things that not all parents did. It was our real education in many ways.
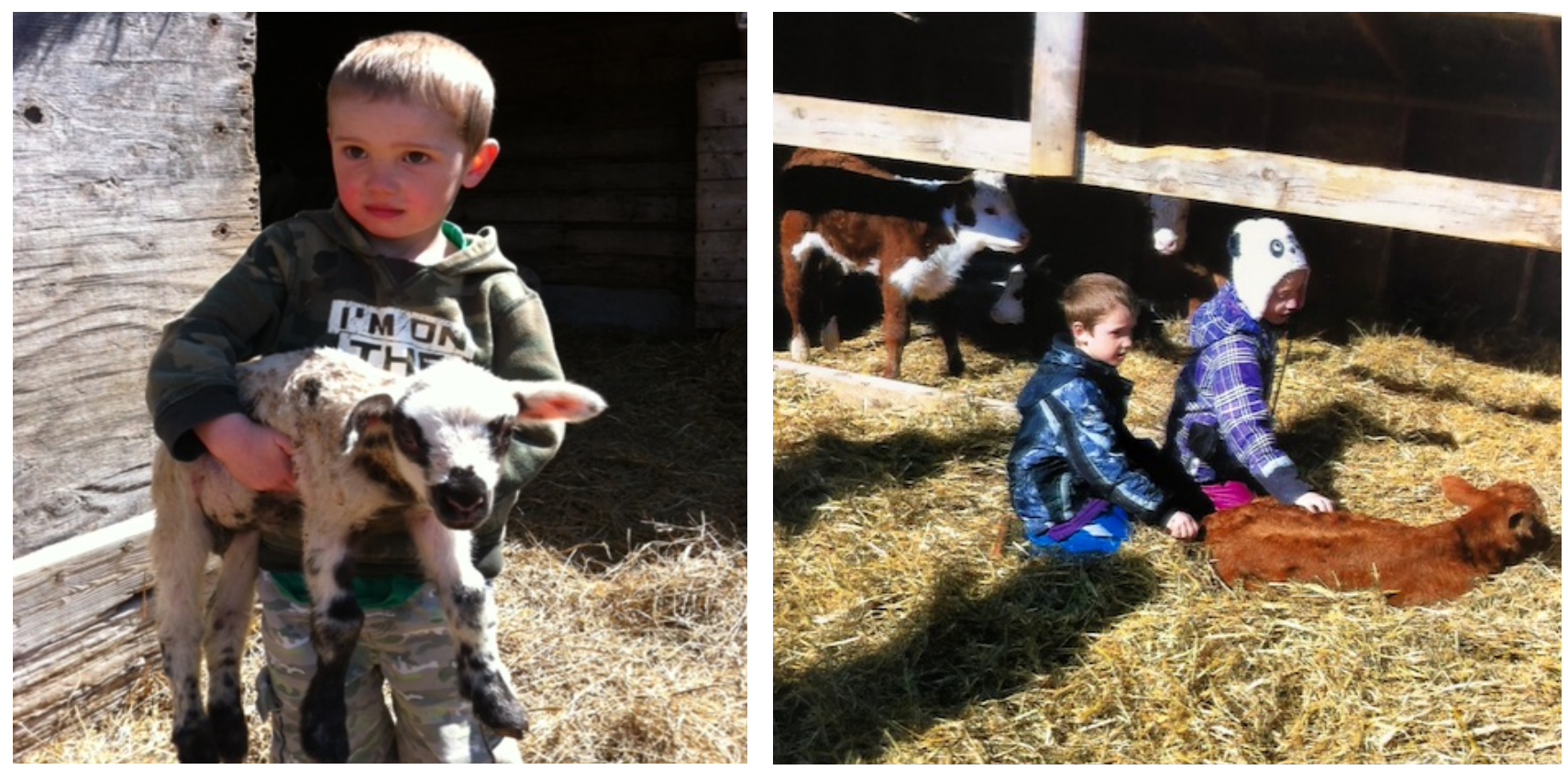

Fig. 1 and 2: Becoming acquainted with a newborn lamb and calf

I started driving both the Chev half-ton (stick shift) and tractor at nine years of age. I still remember having to stand up to push the clutch to the floor on that Massey. Many Saturdays were spent picking rocks and roots with my older brother, sister, and dad. I'd drive tractor using the hydraulics for the front-end loader because I was not big enough or strong enough to pull tree trunks and carry stones. We would return filthy and exhausted, blackened_face, hands, and clothes_-from the char and loam. For many summers, we did this weekly - until that part-of-the-section was "clean" land. This labour was part of the responsibility of living on a farm. We didn't earn money for it, and we would never have imagined saying "no." There was no allowance in those days as such activity was imbedded in a particular way of life. Besides, there wasn't much to buy in 
the 70s with only one or two general stores in town. If I wanted clothes, I sewed them, including jeans, dresses, and swimsuits. I also sewed for others-doll clothes, children's clothing, even prom dresses-and earned money this way from elementary through high school.

Weekends included activities with aunties, uncles, and cousins from either mom's or dad's side. Sundays were days of rest and were always spent with family and nature, being active, and with lots of picnics. I felt as comfortable swimming in a lake, walking the pasture, or tending the animals as I felt in the house, as there was little time spent indoors except for eating and sleeping. In winter, my dad would remove snow from a local pond, a neighbour would haul in bales, and surrounding families would spend Sundays and evenings skating, cooking wieners, and drinking cocoa. In the summers, with cousins and neighbour kids, we swam, rode horses, and played ball, hide'n seek, anti-l-over, cops'n robbers, and stroke-a-back. In the winters there was sledding, tobogganing, skiing, and lots of indoor games-Cribbage, Checkers, Chess, Rap-rummy, Rumoli, Yahtzee, and so on. Doing quick addition; calculating the odds, sequence, and probability; prioritizing strategies; and tracking cards were basic skills learned at a young age, and practiced to an older one, with multi-generations playing Kiser, Whist, and King Pedro at several tables during the holidays. Play animated us and so our lives.

Sibling negotiation was an ongoing reality as I was the middle of five living sibs. We had to share, take turns, sometimes go without, and always look out for one another, often not tattling as that could bring reprimand to all. Life called for continuous imagination and innovation-turning pots and pans into drums, buildings, or witches' cauldrons-because there was no Lego, Easy-bake ovens, or Toys R Us. Rocks, sticks, and broken dishes became a number of things depending on the day and the imaginary play we assumed. Too, there were endless mud pies, adorned with branches, bones, feathers, berries, and stones - a recipe that was passed among cousins, sisters, and neighbour-friends-a staple for our father for more than a decade (as I have three sisters). It was a rich imaginative and imaginal life that never permitted boredom or aloneness.

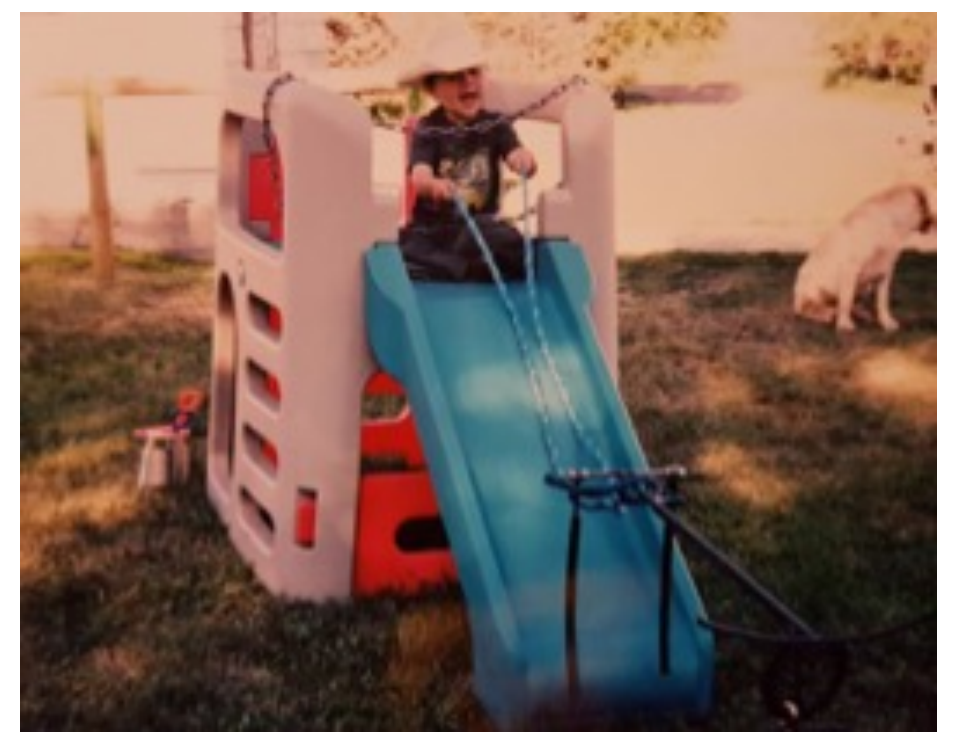

Fig. 3: Plastic play-structure transformed through imagination into a chuckwagon with a team of horses 
Play builds confidence and resilience—both of which arise from agency. "Play is a safety valve; it enables a child to get rid of his feelings, and a child's feelings often shock parents" (Hern, 2007, p. 43). Parents, despite their urge to interrupt and "correct" the play, "should not interfere" (p. 43). In addition to emotional release, play allows the working out of difficult situations-that is, more satisfactory resolutions via reiterations. Play encourages creative and critical thinking of both the divergent and convergent forms. "The importance of play, and the imperative to let children figure things out on their own," writes Hern, "has been obscured and layered over by a noisy cultural demand for supervision and maintenance" (p. 43).

Because of limitless potentialities, I had free rein in the shed with the grinder, welder, and vice; in the barn with horses, cows, and bales; or in the house baking, crafting, and sewing. Each place was its own kingdom, with a wealth of subjects and its own governance. In a flash, Shep, the loving German Shepherd (family dog of my childhood), could become whatever he was needed to be-a prince, dragon, or faithful companion. Boundaries kept us safe and encouraged us to imagine, build, and discover. Stories told about the child who ... or the neighbour who didn't . . . instilled just enough fear that we knew to stay back from augers, to turn off machinery before touching it, and to be cautious around animals. Yet, we had enough trust and safety in our relations with our environment to jump in without careless thought for knowing had been deeply engrained through personal and vicarious experience, creating boldness, and fostering perseverance.

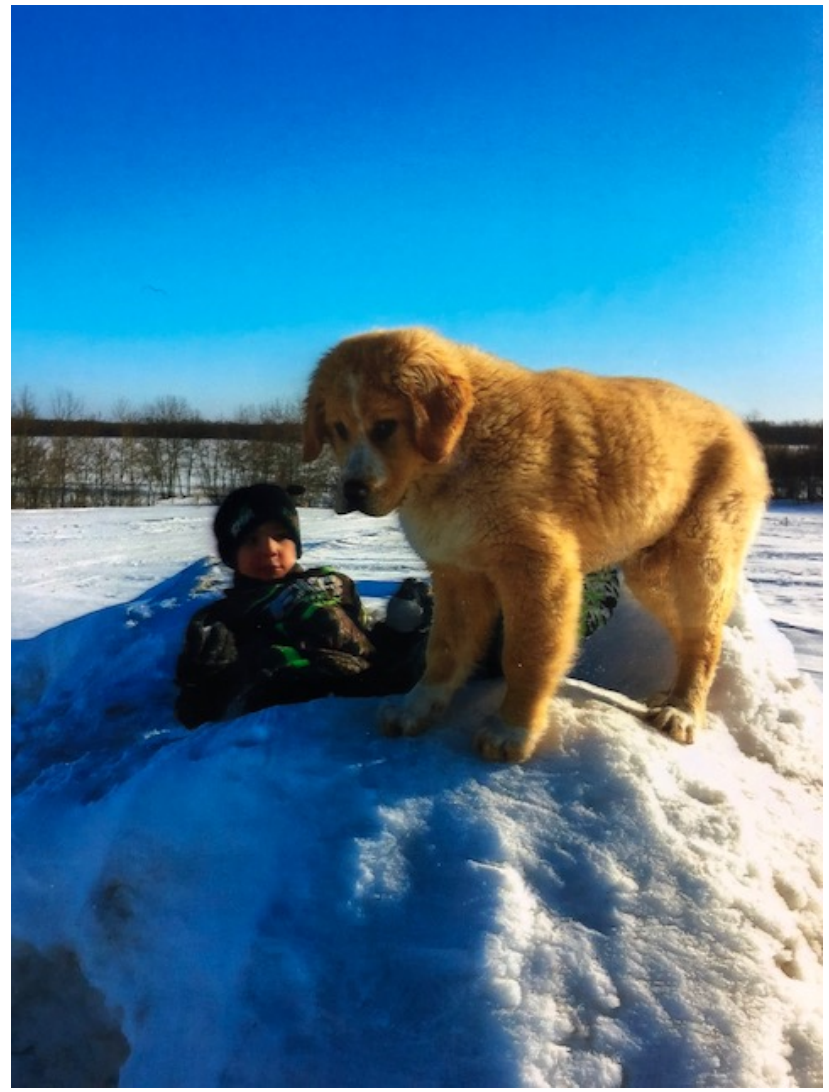

Fig. 4: Beloved dog, Buck, is sentinel over all play 
It was a given that nature was integrated with human life-even writing this as if it was a thing acquired is faulty. It always already was. Stated more accurately, there was no separation between Nature and human existence, it was one and the same; yet, we did not have influence over Nature. It shaped us and so we were second. Such relationship with Life not only included place, but also animals, insects, weather, and trees. And, while not as primary for me, the same could be said for inanimate things like the hoe, whose handle was familiar or the reins of a bridle that were well known. All things were imbued with deep reverence and respect, creating within us a firm footing in life. A foothold, which for me became the basis of adopting Buddhism and then process philosophy as orientations in my teaching and research. That is, this symbiosis filtered not only into daylight consciousness, but also "into a living sense of a dynamic relationship" with Nature wherein disease and death also dwelt (Cobb, 1959, cited in Chawla, 1990, p. 19).

The effects of such childhood memories have been explored by various authors including Theroux (1980), who remembers the cockleweeds and their effect in day-to-day terms:

Could it be, and this is the question of a speculative, unmarveling adult, that every human being is given a few sights like this to tide us over when we are grown? Do we all have a bit or piece of something that we instinctively cast back on when the heart wants to break upon itself and causes us to say, "Oh yes, but there was this," or "Oh yes, but there was that," and so we go on? (p. 55)

To that relationship, Lewis (1960) owed "a certain fund of calm within myself . . . which I am able to draw upon in an emergency" (p. 36). For Spender (1951), who spoke of the exceptional harmony of his childhood setting, it "enabled me to retain throughout life a central calm and happiness, amid violent divisions of my own nature" (p. 311). And perhaps most eloquently for Thurman (1979),

I had the sense that all things, the sand, the sea, the stars, the night, and I were one lung through which all of life breathed. Not only was I aware of a vast rhythm enveloping all, but I was a apart of it and it was a part of me. (p. 226)

He further adds, these experiences

gave me a certain overriding immunity against much of the pain with which I would have to deal in the years ahead when the ocean was only a memory. The sense held: I felt rooted in life, in nature, in existence. (p. 8)

Based upon autobiographies read throughout a long lifetime, Edith Cobb, in an essay (1959) and book, The Ecology of Imagination in Childhood (1977), claims that communion with a place evokes elation. Emphasizing the importance of remembered encounters with the landscape in childhood, she traces a line of influence that nature-the trees, tumbleweed, and terns that creative thinkers encountered as children and the quality of such encounter-has upon their thought as adults. "Their thought, in turn, affects the course of our culture" (Chawla, 1990, p. 19). That is, at the root of creative unfolding and advance, are the conservative effects of remembered landscapes. And further, their relationship with nature served as a touchstone for creative renewal. 


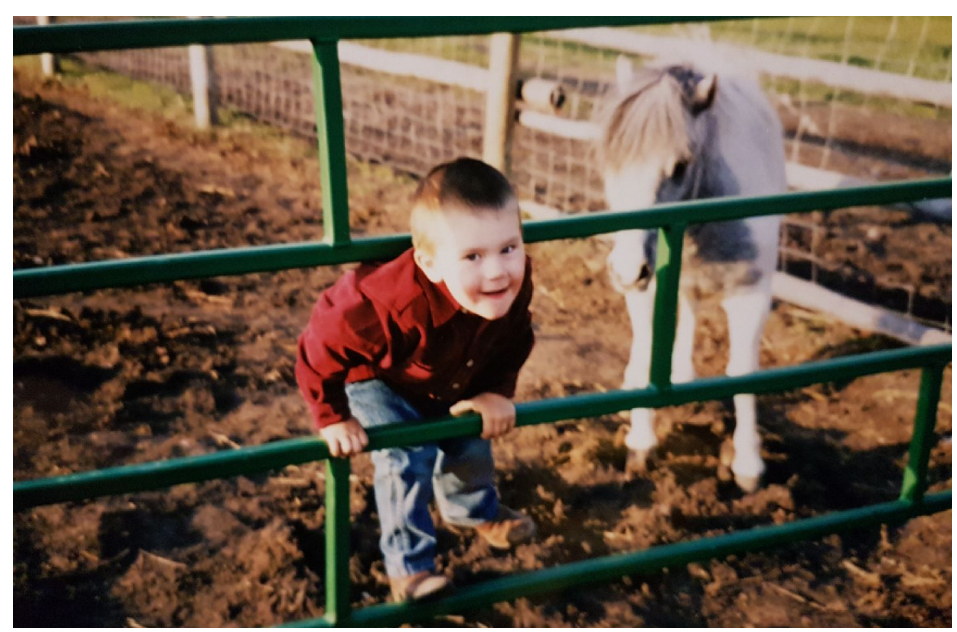

Fig. 5: Young child at home with his pony and farm surroundings

"A renewal of relationship with nature as process" (Cobb, 1959, p. 539) means openness to a process from both sides of nature-death and hardship as well as birth and delight. It is reasonable to suppose that some of the effort they inspire are "attempts to perpetuate the essential conditions of this relationship" (Chawla, 1990, p. 19).

Such living ingrained, within my sibs and I, an unspoken awe for the patterns, wisdom, and traditions of life, while remaining open to the unpredictable and emergent. For example, when Baba insisted on putting fresh cow manure on a bad bruise or cut, we willingly stuck out our leg. Only in present reading have I learned that manure's microbial components included antibiotic-like qualities (Mucz, 2012, p. 59). Just as wild animal fats were used in home remedies to treat skin problems (p. 59), and milk (raw) was especially important for respiratory and digestive problems (p. 57). We existed because of regard for Other - that is, we were all tied up together through interdependence, relational connectedness, and relational accountability with place. We survived by virtue of knowing with animals (both domesticated and not), land, and weather. And, in turn, we have flourished because of such insights and continued renewal via the fecund particularities of place, especially in regard to creativity-the rich, raw material for writing, and reflection as well as a practiced way of perceiving the world-a habit of both being and seeing. As Cobb and others have suggested, the legacies of ecstatic memories alone are notable: meaningful images, profound relationships, an internal core of calm, a sense of integration and oneness with nature, and for many, a creative disposition (Chawla, 1990, p. 22).

For Diane Ackerman (1999), the "ecstatic form of play" is "deep play" (p. 12). She adds, "in its thrall, all the play elements are visible, but they're taken to intense and transcendent heights" (p. 12). She also calls it "transcendent play" - a deeper form of play, "akin to rapture and ecstasy, that humans relish, even require to feel whole" (p. 12). As such, this quality testifies to "how something happens, not what happens"; thus, activities like creative process, risk-taking, "communitas" (with imaginal figures, animals, nature), and some sports_-bale leaping and horseback riding-involve the "sacred and holy" (p. 16). Importantly, Ackerman turns to the ancients to differentiate between "rapture and "ecstasy" - the former, literally, being "seized by force" as if caught in the talons of a hawk or "raptor"; and the latter, for the 
Greeks, "meant to stand outside oneself" —yet, deeply through self so as to join with Other, in a fleeting encounter (p. 16). Said otherwise, "rapture is vertical, ecstasy horizontal" (p. 15); ecstasy connects with other entities on the ground, not in the sky.

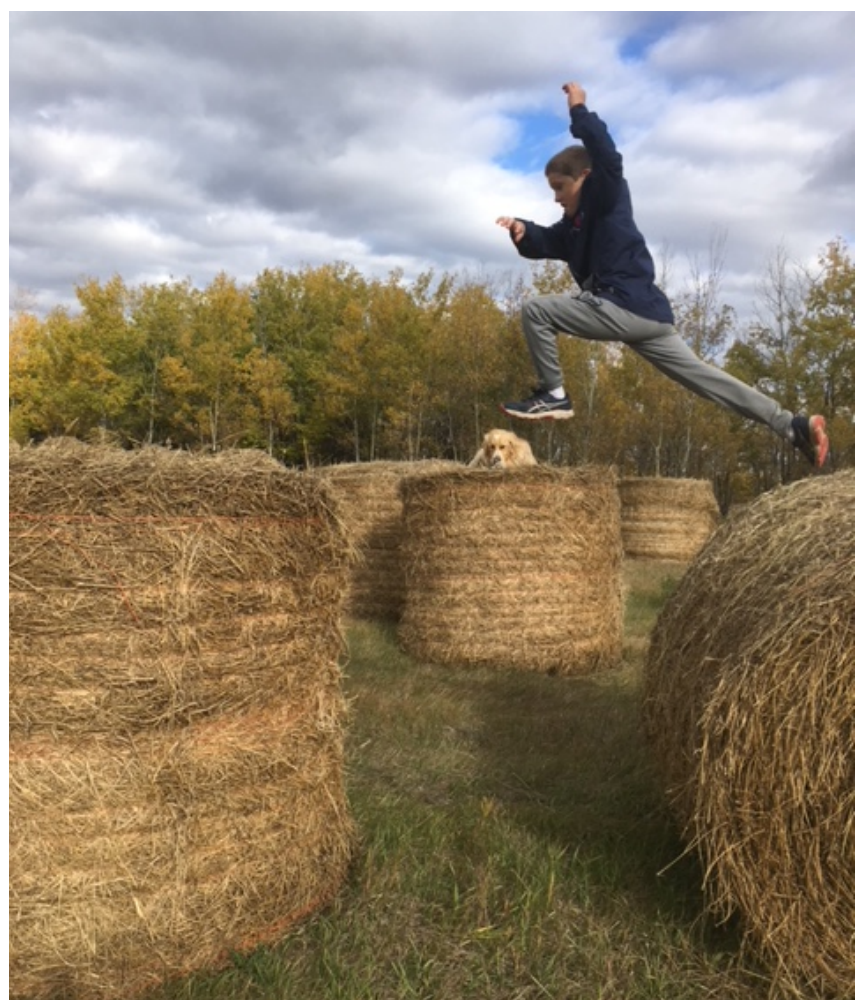

Fig. 6: Deep play—bale leaping (with Buck overseeing on a bale in the background)

As kids, our conversations included comment on wind and animal behaviour. If something seemed out of place, we asked about it and explored it as a collective query. If the wind switched to the east or southeast, it would bring rain. When chickadees and white-tailed deer fed early in the day and for longer periods, a storm was coming, and when coyotes howled at night, it signaled continued good weather. There was a symbiotic relationship with every element among which we lived. Such knowing also included our farm animals, for when the dog rolled it meant rain and we'd tell our parents immediately, leading to quick work with haying or picking garden bounty. Often others' decisions regarding hay were verified by a phone call to my mother to ask about forecasted rain. To this day, my mom, 82, has throughout her life and her mother's before her, tracked hoarfrosts on a yearly calendar. Recorded as light or heavy, six months to the day meant rain. Just as the first thunderstorm in spring, plus 110 days pointed to the first killer frost. When I was young, this kind of wisdom was a typical thread through conversation, be it with grandmothers, between neighbours, or across a local community as still witnessed among expat Saskatchewanians. Today, we have lost the art of reading nature's signs and with it the kinship and grounding of an ecology of relationship.

Too, play and work often coexisted. Our chores and games required lots of physical movement, mostly free, but also the kind that built muscle, stamina, and discipline. They demanded commitment because 
one action depended on the completion of another and the gestalt meant survival. The daily walk to bring the cows home from pasture was accompanied by a narrative of heroic conquest. As I made the journey across the slough, the quest required only stepping on the hummocks and always sidestepping stinging nettle. To miss a hummock was death by alligators or gladiators. So there was risk involved, both real and imaginary, and the necessity to muster up the courage to carry on. This attitude did not supersede the necessity to feel what was happening in the moment and to know what was required-but that too, taught us to work at the edge of our abilities-perhaps these experiences contribute to what taught me to set high yet attainable expectations for my students, the encouragement and push to excel. To this day, I can still touch the deep cellular fear that needed to be confronted in order to get into the pen with a bull or bring one home from pasture. These trips often included loving talk with the animal and a pact made with the divining creative principle, both agreements made to ensure my safety.

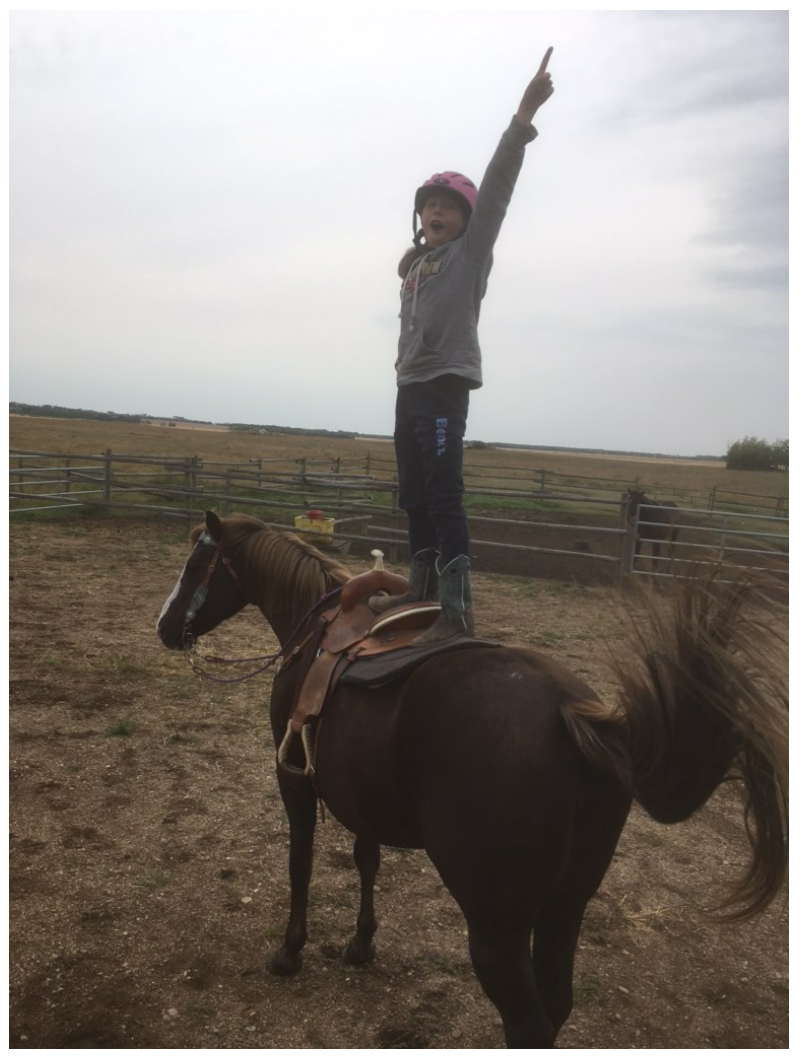

Fig. 7: A trusted, familiar friend, Cisco (horse), encourages bravery and balance

In relation to the realm of play, our parents played with us as did two sets of grandparents. Cricket, scrub, catch, skiing, and snowmobiling were activities led by our father during which our mother would read in the rare quiet of the house. When we were younger, our mom played in the house with us as this age and place was her domain. However, they worked as a team-both strict, insisting on good manners, respectful speech to our friends' parents, and all neighbours. As rural life was isolating, we had to rely on each other so things were shared, goods bartered and traded, and strong social relations were established and maintained. 
The way of life of the family farm was strengthened by regular visiting, which included meals, games, dancing, and rye and coke - that is, for the adults only and then, well into the evening. Visiting included the whole family coming to your house (or you going to theirs) so both adults and kids developed sustaining relationships. Visiting was a well-timed staple until I left home a few weeks after high school graduation. Visiting also included intergenerational conversation, socializing, and storytelling. In general, any adult could correct any kid-adult-word ruled and they stuck together. If you did something bad, you knew that if caught, you would get it twice, as one set of parents would tell the other. Visiting educated in select ways. We were taught to listen, to wait our turn, be respectful, be patient, be kind, be helpful-that is, always ask what you can do for another, even if you arrived after a meal, you were expected to pick up a tea towel and dry dishes. We were taught to step up, help whoever and wherever it was needed. I remember especially enjoying stories of when my mom and her older brother, Uncle Lawrence, were kids-they were incredible, magical even-the chestnut mare (who lived to be 28 years of age) who faithfully cared for them, walking to school during bitter snowstorms. The kids, bundled-up-blind-in-blankets, knew when to dismount because the horse would stop.

My father was is a musician. There was live accordion music all the time. Other musicians stopped by weekly with violins, banjos, mandolins, and guitars, so it was typical to spend many evenings dancing around the house with the dog howling outside. Dad also played in a band that entertained in community halls so I grew up dancing polka, two-step, butterfly, waltz, and schottische. I loved watching the farmers transform with Brylcreem, dress pants, and polished shoes or cowboy boots. It seems a dream now, these first-generation Eastern European farmers turn graceful leads as they swung their partners through the air, their own feet barely touching the shiny, waxed, wooden dance floor. Even in the dance hall, when not twirling at the front by the stage, the kids were in the kitchen helping to prepare the midnight lunch.

Everyone in the area attended, young, old, disabled, diseased, forlorn-but they were not seen like thiseveryone was a neighbour and was known by name. We learned empathy, compassion, appreciation, and grace. I especially remember learning the feeling of gratitude-it was a palpable thing that I could feel whenever there was a community gathering. Despite individual hardships, losses, and heartbreaks, everyone danced, visited, and ate. I recall on the drive home asking why someone was like this or that and in response being told a story about something that happened to him or her or their parents-the stories were sad for they were about misfortune, calamity, or transgression. From a young age, the stories and lives of others taught me that in this wide web of relations, there were hard fates and sorrowful endings, and for every grace granted, gratitude was crucial. The justice of kismet along with Nature's lawfulness was a given-it was not good or bad-it was. To many, this code might seem cold and impersonal, but it kept us close to the pulse of Life. It kept us humble. And it kept our hearts open. Life didn't unfold as we wished or wanted. It was is much more complex and indeterminate. Life itself taught the impermanence of things. 


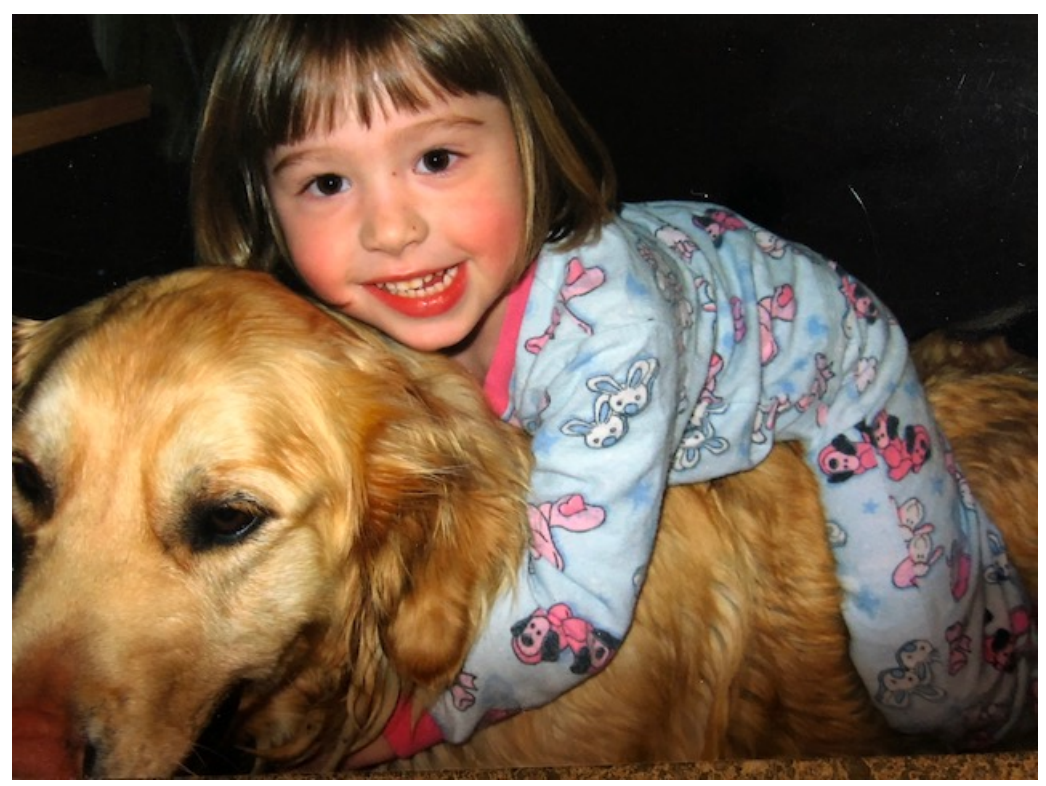

Fig. 8: Joyful child who loves her dog, Norm, and learns trust and belonging through him

Stories were used to both socialize and subvert-that is, some revealed opportunities beyond the norm. While many of my relatives lived familiar lives, I had a few exceptional female cousins. One in particular piqued my curiosity. She had gifted me with a small doll with auburn hair and green eyes. My other dolls were blond-haired and blue eyed and somehow my scissors always found their way into the silky, whitish manes. But this doll with soft tan skin, I loved. It was the only gift that I remember receiving from her, yet my mom says she often gifted. She visited at Christmas but everything else about her was mysterious, foreign. She had joined the Canadian Armed Forces when she was young, trained as a registered nurse, and lived on base in Labrador. In hindsight, I suppose this doll, who shared a resemblance with me, would have been experienced as if my cousin saw me. That is, I was seen. Perhaps more by her than by my mother, because why else would I get a blond, blue-eyed doll year after year for Christmas. I remember crying my eighth year when I received yet another from my mother. Surely, it was a mistake-this doll must have been meant for my younger sisters, as I did not want it. In fact, the brown doll was one of only a few things that were still stowed safely away, surviving all these years in a trunk stored on the family farm.

Today, I live across from a block that is open green grass with several robust 60-year-old spruce and tamarack. The park backs onto woodland and a creek. It hosts multiple ball diamonds, with a skating rink at one end and a curling rink at the other. In the latter, I see mostly retired adults, and in the former, I see parents drive up with kids and hockey gear. I rarely ever see kids in the park and there are never families_playing. There is organized softball but no pick-up games of scrub, no kids batting the ball around, no parents and kids playing catch, or using the backstop for practice. There are two young families on my avenue who have walked over a few times to swing their young children. However, I see no kids playing, or hanging around even though there are a junior high and two elementary schools within a few blocks. In fact, I am struck by the lack of play in my neighbourhood. I never see kids with bikes, Frisbees, or toys on the grass or in the sandboxes. Mostly adults walking their dogs use the park. 
What has happened to play? Play in relation to places that lay a claim upon us_like the farm, fields, and roads of my youth —and to places constructed exclusively for urban play_like parks and playgrounds?

In Homo Ludens (Man at Play), Dutch historian, Johan Huizinga (1949/2016) defines play as the central activity in flourishing societies. The Latin word Ludens derives from the verb ludere, which is cognate with the noun ludus (OED, Ludens). Ludus has no direct equivalent in English, as it simultaneously refers to sport, play, school, and practice. Linguistically, "[p]lay is a thing by itself" (Huizinga, 1949/2016, p. 45). Further, the "play-concept as such is of a higher order than is seriousness. For seriousness seeks to exclude play, whereas play can very well include seriousness" (p. 45). Huizinga takes the view that "culture arises in the form of play, that it is played from the very beginning" (p. 46). Even the activities that aim at satisfying vital needs, such as hunting, "take on the play-form" (p. 46). It is through such playing that society expresses its interpretation of life and the world. Taken further, he sets play and culture side by side, discusses their "twin union," but insists that "play is primary" (p. 46). "All the basic factors of play," individual and communal, he argues, "are already present in animal life" —

to wit, contests, performances, exhibitions, challenges, preenings, struttings, and showings-off, pretences and binding rules. It is doubly remarkable that birds, phylogenetically so far removed from human beings, should have so much in common with them. Woodcocks perform dances, crows hold flying matches, bower-birds and others decorate their nests, song-birds chant their melodies. Thus competitions and exhibitions as amusements do not proceed from culture, they rather precede it. (p. 47)

Huizinga identified five characteristics of play: it is free; it is not "ordinary" or "real" life; it is distinct from "ordinary" life both as to locality and duration; it creates order; it is connected with no material interest, and from it no profit can be gained. Of note, is the first characteristic: "free," perhaps more precisely, "freedom." By "free," Huizinga means without compulsion, but he also means without constraints, with the spur-or-the-moment spontaneity that most of us can remember. Supervised, organized play, for Huizinga, is "play to order," lesser play at best; at worst, not really play at all.

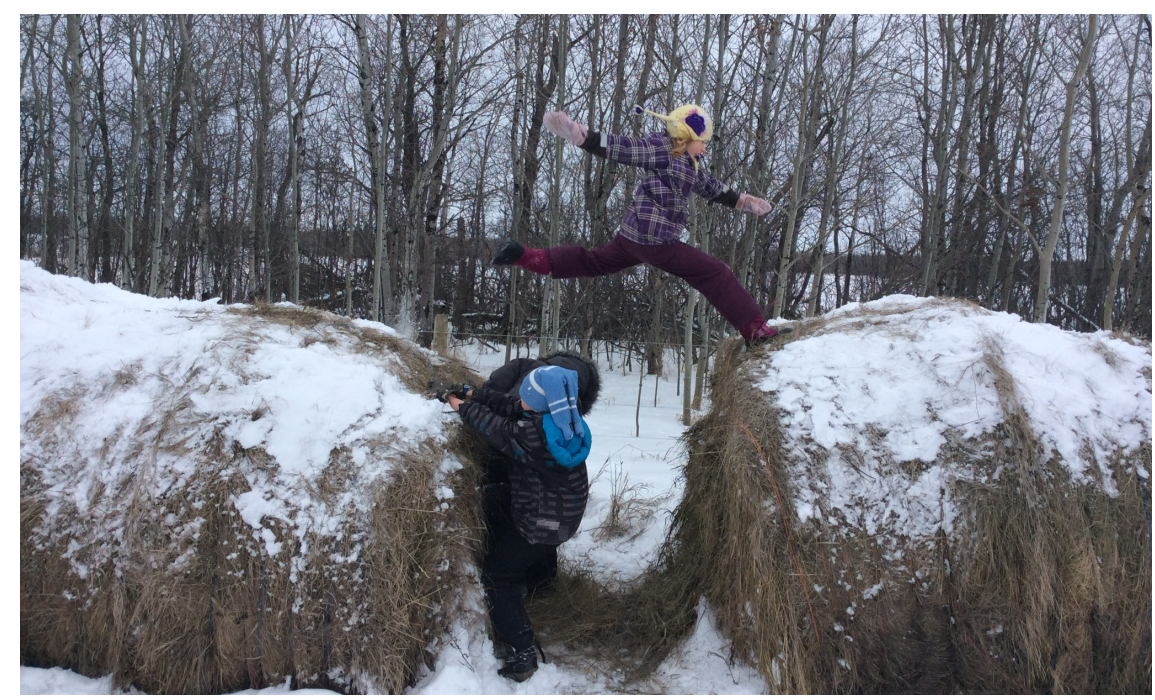

Fig. 9: Free play, deep play—sister and brother bale leaping—and learning to trust their own bodies 
But more and more supervised play is exactly what kids are getting. Bicycle helmets for children have become commonplace. Although when I see adults on European-style bicycles, with helmets, the image strikes me as peculiar. Many of my summer memories as a kid were with bikes. I had claimed an old, blue, ten-speed that got stuck in higher gears and had no brakes. I must admit running those narrow tires over rough gravel roads built both grit and tenacity. However, that bike was responsible for a thrill of a lifetime and much valuable conversation. One summer I had the idea to ride up Glendenning's hilla very steep quarter-mile hill that ran out over a washed-out road covered by creek-bed rocks. We pushed up that hill, and one by one let it rip. It was free-falling, no brakes, legs stuck out in both directions, and delicate balancing on one-inch tread as I raced down that graveled hill. I remember squealing, but I don't recall whether it was rush or fear that forced sound out of me. Despite potentially injuring myself, it was exhilarating — an unbelievable feat made real_- "ecstatic, absorbing, rejuvenating" (Ackerman, 1999, p. 17). We didn't do it again, but the wild freedom of that event has lasted for decades, remaining part of my cellular self.

I wonder what the mean age is of kids (in urban and suburban areas) allowed outside alone? Even with friends, the age has risen to the point where, in many cases, it excludes the traditional definition of "kids." F. Scott Fitzgerald's definition of freedom was a child riding a bike on the street without adult supervision. More recently, LeBron James, on the topic of bikes, said in an interview: "It was a way of life! If you had a bike, it was a way to kind of let go and be free." To demonstrate his commitment to this childhood love, when he "helped open a brand-new public school for at-risk children" in his hometown, Akron, Ohio, he pledged not only "a University of Akron scholarship to every student who graduates," but also his family foundation pledged "to provide a free bicycle and helmet to every student" (Gay, 2018, p. 1). He said this in the interview: "Me and my friends, when we got on our bikes, we would just ride," he recalled.

Sometimes we would even get lost, because we'd be gone for so long. But there was a sense of joy and comfort. There was nothing that really could stop us. We felt like we were on top of the world. (p. 1)

The number of kids riding bikes on streets these days is a fraction of the number of adult riders. When I was a kid, an adult riding a bike was an odd sight to marvel. Today, it's adults riding, not kids.

Do you remember the phrase, "Can __ come out to play?" This once familiar phrase did not refer to an organized sport, but simply to play. It was spontaneous and it was fun. We couldn't tell anyone what we were going to do-perhaps build a fort-but the world in which that fort would be constructed was one that would surface in spontaneous, imaginal, free play! Negotiated in that moment among the friends present-through collaboration, compromise, and communal efforts. But today, kids have their activities arranged, planned, and often supervised. Despite ample evidence for play's necessity, "it has not affected how we educate or parent" (McCarthy, 2015, p. 17). In fact, "today most children rarely have ready access to the outdoors and the unencumbered play that this allows" (p. 16). What does this do to our psychosocial emotional development? What happens to the development of the imaginal and symbolic realms if living and learning becomes scripted? The "free time" of children has taken on "a social formality that would have done a Victorian matron proud," writes Jay Teitel (1999) 
in "The Kidnapping of Play" (p. 58). He argues that adults have taken over play for themselves: "Abducting play is only the first part of our crime; holding play hostage, and then returning it to its owners in adulterated form is part two." He adds: "Not only do kids play less than they used to; they also play differently" (p. 56). More and more, over-planned play, like over-supervised play, is what kids get. And, it certainly does not have the necessary element of "free"!

When I return to summer Sundays of my childhood, we didn't know what the day would entail. Come rain or shine, my mom would pack picnic hampers, and thermoses of hot and cold drink. Fishing rods and tackle, ball gear, and swimming clothes would be loaded in the back of our long, buttercup yellow, station wagon. We often went to Kipabiskau Lake (Provincial Regional Park), but the drive there was never predictable. We had this game where my dad would take back roads, off-roads, farm roads, and meander through the countryside-somewhat headed in the direction of the destination, but the trips were always filled with wonderment and surprise. Through my parents' conversations, their observations, questions, arguments, and comments-speaking of crops-quality, production, variation-as well as insects, wild flowers, plants-we developed powers of deduction and prediction by attending the particularities of place. "Sense and thought, observation and deduction, this simple two-step process is the key to transforming [an event] from mind-numbing to synapse-tingling" (Gooley, 2014, p. 3). Likewise, they fostered a sense of adventure even in our backyard. These days had both planned and unplanned elements. Most importantly, they maintained an element of spontaneity. Yes, there were limits in time and space, so to separate it from the ordinary, but no limitations were set on impulse or vision.

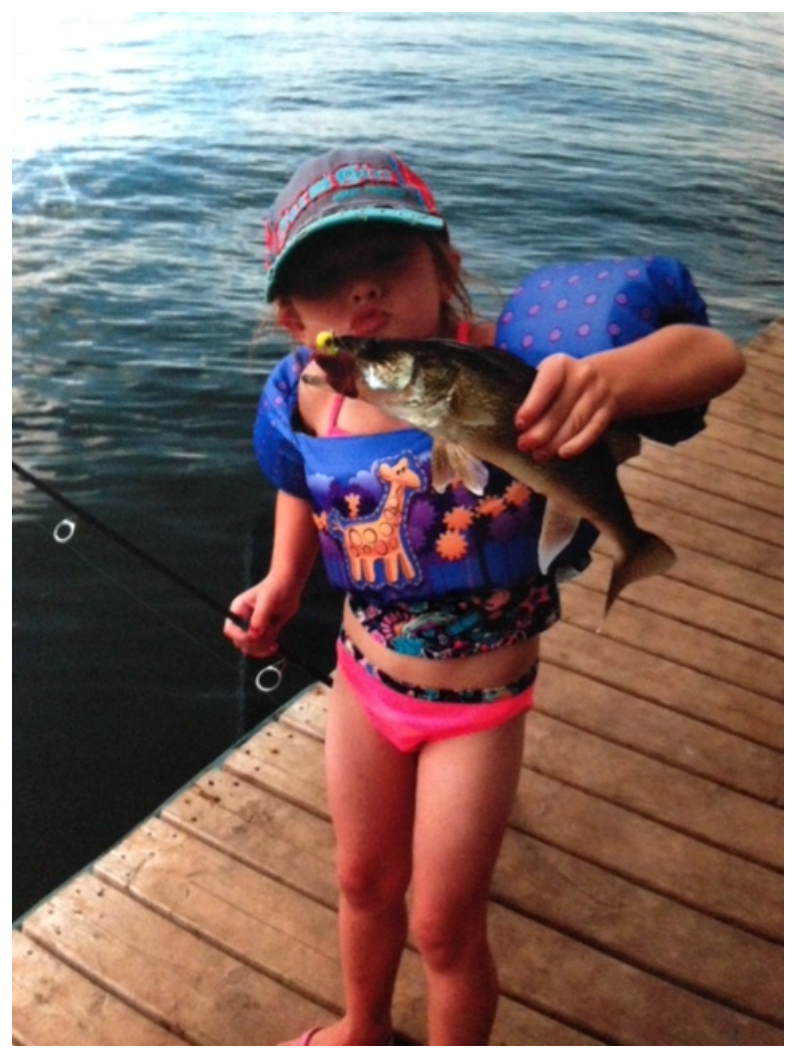

Fig. 10: Ease, comfort, and play_-"Let's kiss the fish!" 
Has play as we knew it ended?

Has the world really changed so much? Or have we?

I consider the rows of cars dropping off one or two children at a time at school. Can kids not walk to school_-if they live within reasonable distance? Is their safety really threatened when walking in a multi-age group? Or unaccompanied by an adult?

I remember my parents telling me that if a stranger came along on the road when I was biking, to get off and walk the bike. I recall being quite uncertain about this advice and asked, "what do I do if the person stops?" "If they need directions or info, answer, but if they attempt to get out of the vehicle, drop your bike and run." Again perplexed, as my bike was a hand-me-down and the only one my size, I grew worried that I would lose it. "Run?" "Yes," my dad said, "Leave the bike and run like hell across the field. He won't catch you." Despite feeling apprehensive about leaving my bike, some kind of alarm was set off in me, something that had never been there before. From then on, there was a mild sense of restriction when riding around the countryside on bikes. But vehicles were few during the day, so for the most part, this activation settled, yet remained a sixth sense toward danger. No doubt this safeguard was given during the 80s when stats were released in Canada about child abductions. I expect my parents thought that whatever we might encounter, we could probably handle. We had grown up developing life skills that prepared us for the unexpected - a kind of natural navigation for being-in-the-world. Thinking ahead, imagining multiple scenarios and ways through, experimenting with trial and error, as well as improvisation, described our daily life. Preparing for possible danger with strangers wasn't really any different. Who could have imagined that I would actually use this instruction 20 years later in Cairo when chased by two young men. When I realized that running down the street wasn't going to save me, and certainly, I couldn't outrun them, I made a sharp perpendicular turn, looked into four lanes of heavy traffic, and headed directly into it.

Does it not seem plausible that in order to have a healthy school, a healthy society, we must raise children who can safely play and learn via their imaginations? "What would our school systems look like if all children and youth could attend well-staffed schools that cultivated cooperation, self-regulation, perseverance, and concentration" (van der Kolk, 2015, p. 350) as opposed to "focusing" to pass exams? Consider the typical cuts from school budgets: drama, theatre, band, music, chorus, physical education, art, even recess, and anything else that involves movement, play, and other forms of joyful engagement. Not only are these subjects absolutely essential to our overall health-that is, emotional, physical, mental, social, and spiritual development-but also they are the very things needed to support traumatized children and youth. As D. W. Winnicott (1971) offered, "It is in playing and only in playing that the individual child or adult is able to be creative and to use the whole personality, and it is only in being creative that the individual discovers the Self" (p. 25) - that is, the spaceless, timeless aspect of our deepest being. 


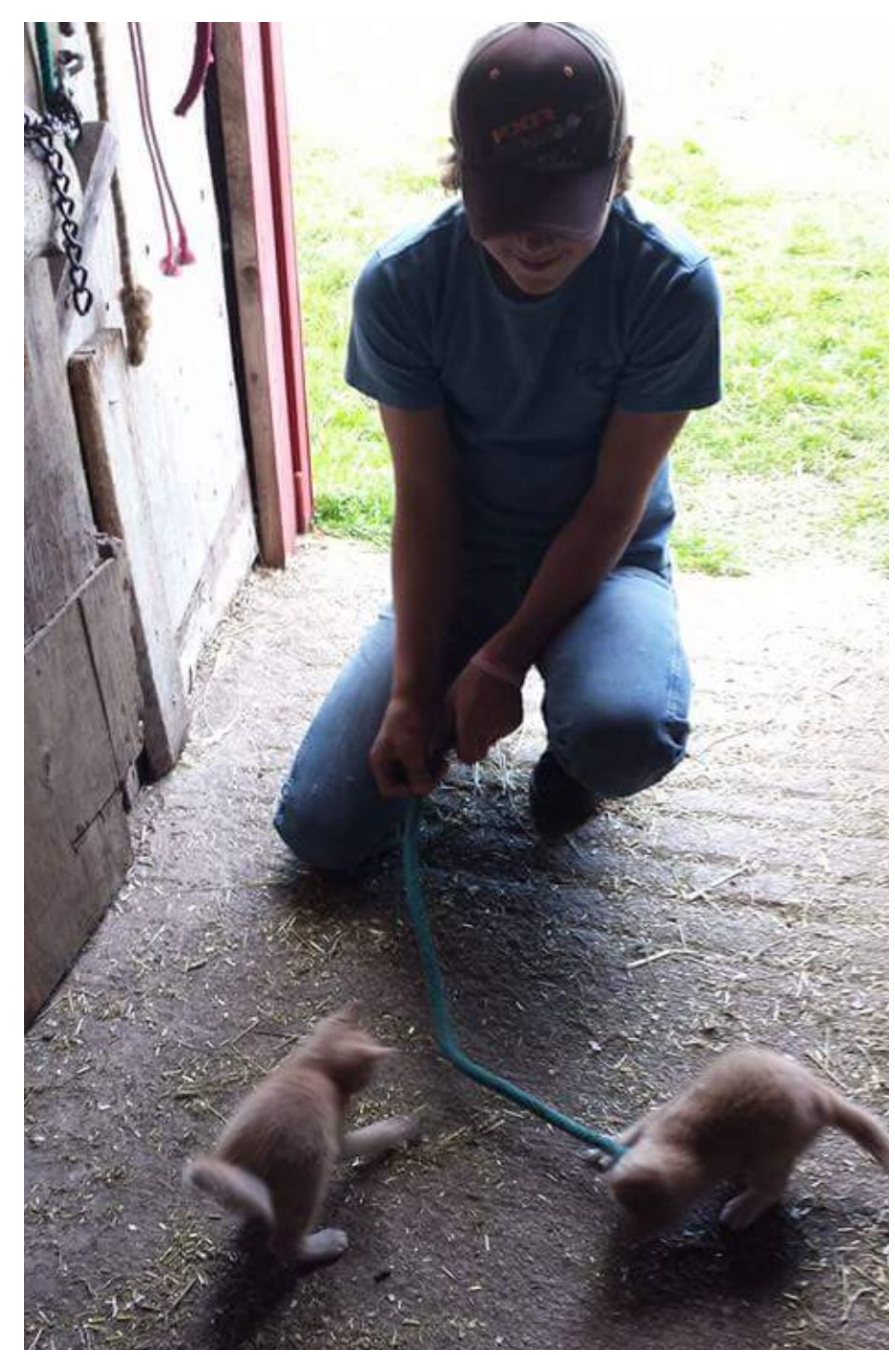

Fig. 11: Simple delight in playing with kittens and perhaps "a creative reaching-out"

Correspondingly, J. L. Rose (2015) argues from her use of deep sand in therapy, "play [is] an irreducible and completely necessary state of being" (p. 53). In tracing the word "poetry" in Greek to create; build, she uncovers it as "dream" from the Saxon for "joy, mirth, music"; "revolution," to turn, wallow, with "wellspring," which shares the same root as "play," to engage oneself, to pledge, "epiphany," and to shine. By extension, "play encompasses poetry as a creative dive towards the core of self and of the world" (p. 53). Further, "play encompasses dream as the unbounded emergence from that personal and collective $\operatorname{core}^{\prime \prime}$ (p. 53). For Rose, in working with children who often come to play more or less disembodied due to trauma or developmental challenges, she advises that when the therapist joins in play, it involves listening, watching, and wondering. Then participation follows, not by way of interpretation, but rather by "whole-hearted companionship" (p. 54). So if the child can come to "fully know or trust his own body, his own feet," this is where dream and poetry can be integrated, "brought to the ground, fully claimed and internalized, ... . [whereby] the revolution inherent in play can heal, with the awe-inspired turn to full embodiment, the healing wallow, the return to the wellspring" (p. 54). Simply stated, "in play, revolution is storytelling seeded in dream, emerging as poetry" (p. 54). 
Today trauma is a major public health issue, "arguably the greatest threat to our national wellbeing" (van der Kolk, 2015, p. 348). Might the loss of play have contributed to the increased prevalence of trauma among children and adults? According to trauma expert, Bessel van der Kolk (2015), "the greatest hope for traumatized, abused, and neglected children is to receive a good education in schools where they are seen and known, where they learn to regulate themselves, and where they can develop a sense of agency" (p. 351). To be seen and known requires being in relationship. It requires the other to be present, embodied, and able to separate what is personal and what is not so as to actually see other, and see without judgment. When a child does not have to defend or protect, she can genuinely free-associate-imagine and play. It is out of this state, Winnicott claimed, that "a creative reaching-out can take place" (1971, p. 75, his emphasis). The "creative reaching-out" of playing, which he understood as the search for self-creative activity as the search for self-contributes to an integrated sense of self when another reflects back that play. For Winnicott, play, reflected back by a friend or teacher, is the creation and validation of a meaningful relationship with the world. That is, when awareness of one's inner reality, and elements of external reality, unite in a safe and trustworthy environment with another who "sees you" - the individual can come together and exist as a unit [that is, as a whole], not as a defense against anxiety but as an expression of I AM, I am alive, I am myself. From this position everything is creative. (p. 76)

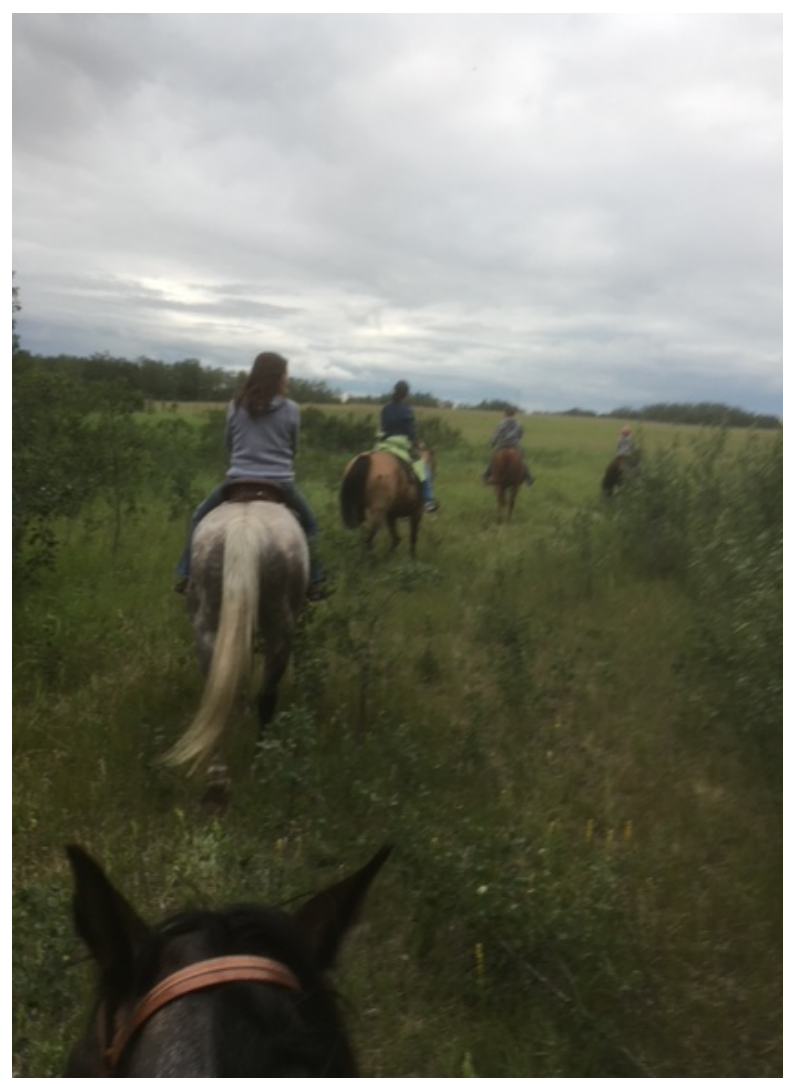

Fig. 12: My sisters, friend, and I on a summer ride down the Sandy Road—35 years later 
"More than anything else," declares van der Kolk (2015), "feeling safe with other people defines mental health"; safe relationships are "fundamental to meaningful and satisfying lives" (p. 352), this includes relationship with place and animals. The critical challenge in a learning environment is to "foster reciprocity" (not equal but mutual): sincere hearing and being heard; really seeing and being seen by other people. Addressing the effects of trauma in kids begins with fostering safety, establishing predictability, and ensuring teachers' capacities to see, hear, and know them. Studies repeatedly demonstrate that, "having a good support network constitutes the single most powerful protection against becoming traumatized" (p. 210). In the same manner, "traumatized people recover in the context of relationships" (p. 210). "Not being seen, not being known, and having nowhere to turn to feel safe is devastating at any age, but it is particularly destructive for young children, who are still trying to find their place in the world" (p. 88). In our living and teaching, we would be well served to look back to our youth, so to reemphasize what gave us comfort and freedom, yet also what taught us risk-taking, responsibility, and wonder. We must remember where we played, what we played, and with whom we played (imaginary, real, animal, or human)—for these elements are the root of our being — so to foster similar conditions for kids today. To create or restore a sense of wholeness in a person, we need to welcome imagination and the body in both play and pedagogical spaces.

\section{References}

Ackerman, D. (1999). Deep play. New York, NY: Vintage Books.

Chawla, L. (1990). Ecstatic places. Children's Environments Quarterly, 7(4), 18-23.

Cobb, E. (1959). The ecology of imagination in childhood. Daedalus, 88, 537-548.

Cobb, E. (1977). The ecology of imagination in childhood. New York, NY: Columbia University Press.

Gay, J. (2018, August 6). The LeBron James Interview About Bicycles. Retrieved from https://www.wsj.com/articles/the-lebron-james-interview-about-bicycles-1533561787

Gooley, T. (2014). The Lost art of reading nature's signs. New York, NY: The Experiment Publishing.

Hern, M. (2007). Watch yourself. Why safer isn't always better. Vancouver, BC: New Star Books.

Huizinga, J. (1949/2016). Homo ludens. London, UK: Routledge \& Kegan Paul.

Lewis, C. D. (1960). The buried day. New York, NY: Harper.

McCarthy, D. (2007). "If you turned into a monster" Transformation through play: A body-centred approach to play therapy. London, UK: Jessica Kingsley Publishers.

McCarthy, D. (Ed.). (2015). Deep play: Exploring the use of depth in psychotherapy with children. London, UK: Jessica Kingsley Publishers.

Mucz, M. (2012). Baba's kitchen medicines: Folk remedies of Ukrainian settlers in western Canada. Edmonton, AB: University of Alberta Press. 
Rose, J. L. (2015). The keys to the world: Revolution and epiphany in deep sand. In D. McCarthy (Ed.), Deep play: Exploring the use of depth in psychotherapy with children (pp. 53-58). London, UK: Jessica Kingsley Publishers.

Spender, S. (1951). World within world. London, UK: Hamish Hamilton.

Teitel, J. (1999, April). "The kidnapping of play." Saturday Night (pp. 55-60). The Rockport Co., Inc.

Theroux, P. (1980). California and other states of grace. New York, NY: William Morrow.

Thurman, H. (1979). With head and heart. New York, NY: Harcourt Brace Jovanovich.

van der Kolk, B. (2015). The body keeps the score: Brain, mind, and body in the healing of trauma. New York, NY: Penguin Books.

Winnicott, D. W. (1971). Playing and reality. New York, NY: Routledge.

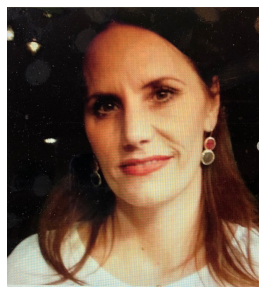

Alexandra Fidyk, PhD, is an Associate Professor in the Department of Secondary Education at the University of Alberta. A transdisciplinary scholar, she teaches curriculum studies, advanced research, and special topic curriculum seminars in analytical psychology, mythopoetics, and trauma studies. She is a certified Jungian and somatic psychotherapist. 